\title{
The Value of an Enterprise Postgraduate Research Programme for creating business start-ups in the UK
}

\author{
Kassandra A. Papadopoulou, Robert A. Phillips
}

Alliance Manchester Business School, The University of Manchester, Manchester, U.K.

\begin{abstract}
The Masters of Enterprise Programme is a postgraduate programme whereby a student attempts to start a business during the course of their studies. Established in 2001, we have analysed the success of the 59 companies created from the course and found that as expected the start-up rate is higher than the general population. We also found that ratio of male to female founders (70-30) was similar to start-ups from the general population; however, the survival rate of ventures created from the programme was significantly higher. Also, a higher rate of the businesses were employing more than just the founder, implying they are what could be considered "Entrepreneurial" businesses rather than simply someone selfemployed as might be normal in some careers. Despite many overseas students completing the course, only 3 of the businesses were founded outside the UK, suggesting the UK economy is benefitting from the ventures created. We also discuss other outcomes from the course such as these entrepreneurial students are often recruited by top corporates. We further discuss what we believe are the contributing pedagogic factors to its success.
\end{abstract}

Keywords: Entrepreneurship and Enterprise Education, Employability, Startups, UK economy. 


\section{Introduction}

Along with employability, enterprise is a key area for UK universities in ensuring workready graduates and the government has recommended all students have some form of enterprise education (QAA, 2018; AdvanceHE, 2019).

In UK there are a number of universities delivering entrepreneurial programmes at undergraduate and taught postgraduate level. According to Matlay and Carey (2007) however, each university uses their own description of what establishes an entrepreneurship education. Though measuring the outcomes and value of entrepreneurship education in the UK is still unclear. There is a debate on the impact of entrepreneurship education upon the UK economy (Maresch et al., 2016; Matlay and Carey, 2007; Gibb, 2008). One of those efforts to measure an outcome for a particular programme; the Master of Enterprise Programme (M.Ent.), a postgraduate research programme whereby a student attempts to start a business during the course of their studies. Alumni entrepreneurs at The University of Manchester have often participated in a number of enterprise activities whilst at University (Phillips, 2018) and a range exist from on curricular courses such as modules within other subject areas to extra-curricular activities such as business plan competitions, boot camps, accelerator programmes and inspirational speaker events (Papadopoulou and Phillips, 2019; Phillips, 2010). There is also a considerable amount of practical support to student entrepreneurs at many institutions.

"Functional" or "system-level" theories view entrepreneurship as a series of actions or a process, than a result such as registering a start-up company, since they highlight the entrepreneur's unique function in the economic system of the market economy (Klein and McCaffrey, 2019). Such theories are a centre of the activity-based, processual research trend in entrepreneurship studies. Many different types of actions have been used to define the entrepreneurial function, including small-business management, imagination or creativity, innovation, alertness to opportunities, the ability to adapt to change, leadership, and judgment (Klein and McCaffrey, 2019).

Looking in general, besides academia within UK, the number of various programmes has grown rapidly over the last few years, a total of 205 incubators and 163 accelerators are currently located in the country, this growth has been facilitated by $£ 20-30$ million per year of public funding from UK and EU and is being spent (Bone et al., 2019). Within the UK economy the number of UK registrations was 381,885 and graduate start-ups were 4,024 (including social enterprises) in 2017, and they account for roughly $1 \%$ of all UK business launches between 2014 and 2017 (HESA, 2019; ONS, 2019).

The authors believe that university activities can boost student entrepreneurship in four ways; 1) improving self-efficacy, 2) inspiring students to think about entrepreneurship as a 
career, 3) providing skills training to allow students to take advantage of current or future opportunities and 4) provide practical help for the nascent business.

\subsection{Aims and Programme Background}

The University of Manchester has a range of activities run by its Enterprise Centre that lead to student start-ups, the one that is studied and analysed in this paper is the M.Ent. with its motto "Developing the next generation of entrepreneurs". The aim of this paper is to focus on the 59 start-ups founded by M.Ent. graduates and asses their contribution in terms of business start-ups and the effectiveness and value of this research programme in terms of survival rates and compare it to the official statistical data of business start-ups mainly to the UK start-ups, linking to the pedagogy of the course where possible.

The M.Ent. aims to stimulate enterprise combined with various disciplines including number of subjects such as business, engineering, materials, computer science etc. This postgraduate research degree (PGR) has been designed to train and support students in developing business ideas from postgraduate research. It is integrated in its enterprise and discipline subject with four taught units and a one-year-long enterprise project as seen in figure 1. The taught component provides the individual with both skills in enterprise and a depth of specialist knowledge that is directly applicable to their enterprise project. The flexibility for the student is to choose elective subjects for example if they want to carry on studying in the M.Ent. their previous bachelor degree area in a business content, or they want to develop completely different skillsets in a completely different area which they did not have the opportunity to study in their Bachelor degree. The one-year-long project comprising of two parts to the research dissertation: a "Subject" theoretical part focusing on researching a key aspect of the proposed business concept and its implementation and "Enterprise" which is essentially a comprehensive business plan for the proposed business venture. The programme's objectives are to extend the student's understanding and knowledge in their chosen field of entrepreneurial work, to teach business, management and enterprise skills and understanding of the business processes applicable to the development of knowledge based enterprises and to expose students to the processes involved in starting up and running a business (The University of Manchester, 2019). The M.Ent. researchers, apart from the programme's content, have other business start-up support opportunities available to them such as extra-curricular activities including competitions, workshops and conferences which are part of the University's enterprise ecosystem, this programme is linked closely to the theories as stated earlier by Klein and McCaffrey (2019). 


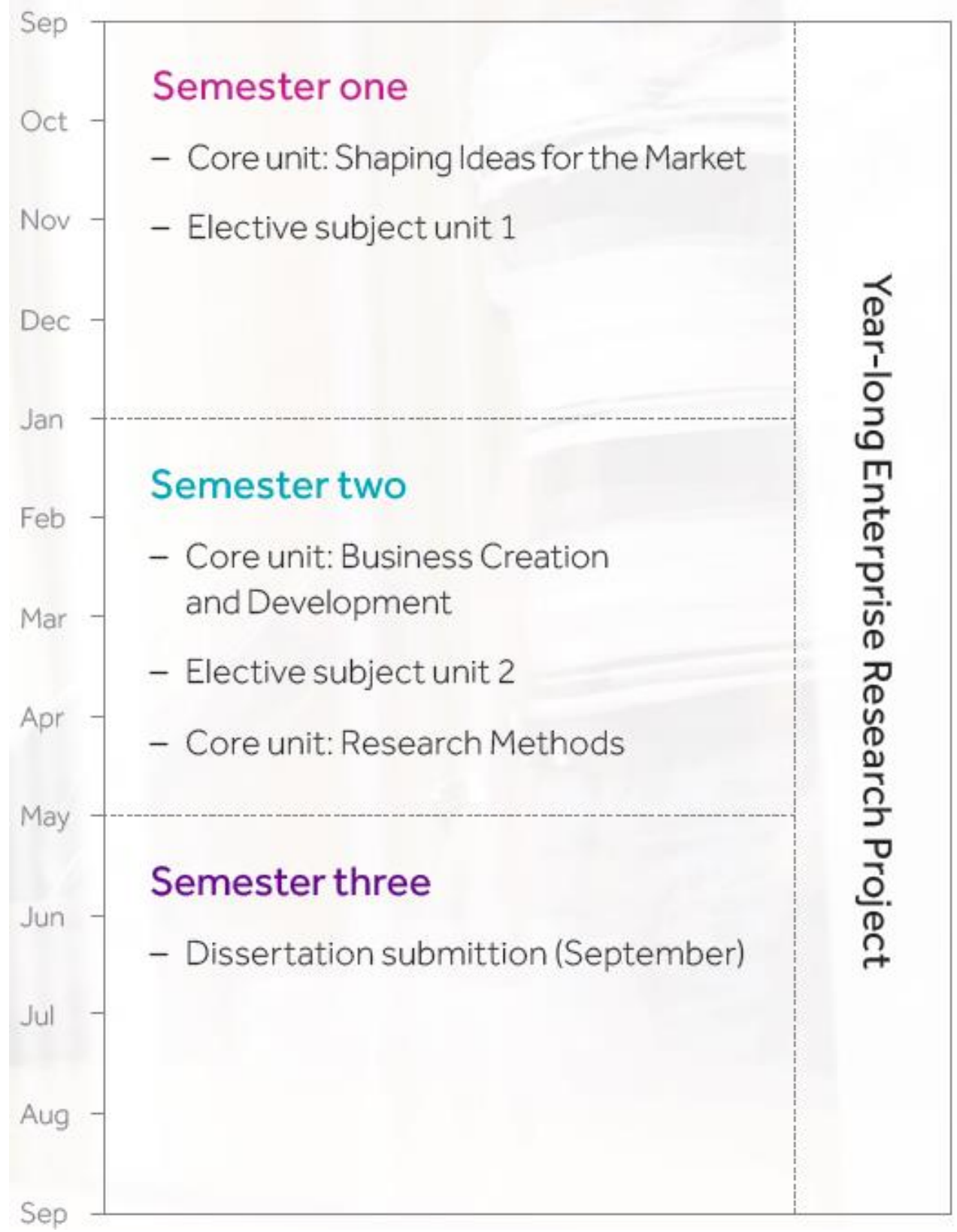

Figure 1. Master of Enterprise 12-month research programme structure. The University of Manchester (2019). 


\section{Methodology}

Secondary data was used from the University's enterprise database (Papadopoulou and Phillips, 2019) for student start-ups - all known student businesses were identified e.g. linked to postgraduate study, business plan competitions, boot camps or any other activities that they may have taken part in and only individuals that studied on the M.Ent. were selected. The M.Ent. programme, first run in 2001, with the first students graduating in 2002 and the database includes information between the 2002 and 2019 which is a period of 17 years. The database includes 59 M.Ent. start-up companies, in total approximately $1 / 3$ of all the M.Ent. students start a business. This database was used to compare survival rates in UK using the Global Entrepreneurship Monitor (GEM) (Hart et al., 2018) which includes data from 2002 to 2018 a period of 16 years. Both databases have: a similar time range, similar time length and geographical location making them very relevant for a comparison study. It should be noted that the M.Ent. students have business intentions hence they are self-selecting this programme and in this study the focus is on practical aspects.

\section{Results and Discussion}

The main results show the percentage of start-ups, gender of founders, the employment (jobs) created and survival rates of start-ups three and five years from their registrations. Table 1 summarises the main results from the analysis of the M.Ent. database and comparison with the UK data from various national data sources that are discussed in this section.

Table 1. Comparison of M.Ent. and UK economy data.

\begin{tabular}{lcc}
\hline Activity & M.Ent. & $\begin{array}{c}\text { UK data (GEM, } \\
\text { APPG, SBA, ONS) }\end{array}$ \\
\hline Setting up a start-up company (start-up rate) & $33 \%$ & $8 \%$ (GEM) \\
$\begin{array}{l}\text { Gender of business founders ratio (Male/Female) } \\
\begin{array}{l}\text { Businesses created that employed more than just the } \\
\text { founder }\end{array}\end{array}$ & $73 / 27$ & $70 / 30$ (GEM) \\
$\begin{array}{l}\text { Start-up Survival Rates 3-year } \\
\text { Start-up Survival Rates 5-year }\end{array}$ & $83 \%$ & $10 \%$ (APPG) \\
\hline
\end{tabular}




\subsection{Setting up a start-up company}

From the M.Ent. course, approximately 33\% of students start a business during the programme or after graduation. According to GEM data, in the 18-25 year old group in the UK general population, start-up rate is approximately $8 \%$ (Germany is $4 \%$ and France $2 \%$ ) (Hart et al., 2018), whilst from the university as a whole, those starting a business (including professions where it is normal to be self-employed) on graduation is approximately 5\% (APPG Report, 2018). Furthermore, approximately only $10 \%$ of these (i.e. $0.5 \%$ of total university graduates) are what we might consider an entrepreneurial startup rather than in a career where it is normal to be self-employed. Hence this shows a much higher percentage for the M.Ent., although as mentioned the students are self-selecting this programme.

\subsection{Gender of business founders}

The M.Ent. has 59 businesses in the database, 43 of them founded by men and 16 by women, hence male founders are more than double of the female (around 2.7 times), (73\% men, $27 \%$ women). There were 36 individual male founders and 13 individual female, indicating additionally that more male than female had multiple businesses. This compares to GEM data which shows that in the general population female start-up rate was $5.2 \%$ and for male founders was $10.5 \%$ (Hart et al., 2018). Therefore male founders are approximately double that of female founders. This gender gap is roughly the same for different stages of business as well. France and Germany also show that female start up rate is about $50 \%$ of male, however the US shows that female start up rate is about $75 \%$ of male.

\subsection{Employment created}

From the database the total employment created by the M.Ent. in the last 17 years is 349 , which is an average of 5.92 people per business, including the founder and an average of 20.5 jobs created per year due to M.Ent. (1.7 jobs created per month). Breaking this down by the founders gender, the total employment created by male founders is 282 (including the founder), each male founded business employs on average 6.56 people (including the founder). The total jobs created by female founders 67 (including the founder), each female founded business employs on average 4.19 people (including the founder). Male founded businesses employed more people on average, however, the percentage of male and female founders who were employing others were similar. Looking further into the growth of the startups, 41 of the 59 start-ups employed more than just the founder $(69.5 \%)$. Breaking this down in gender, 30 of the 43 male founded businesses employed more than just the founder (70\%), and 11 of the 16 female founded businesses employed more than just the founder $(69 \%)$. With a large percentage of the businesses were employing others at $69.5 \%$, this suggests that a significant number of the businesses are "high growth, entrepreneurial 
companies" rather than simply self-employed lifestyle businesses. Data from the 2019 APPG report suggests that graduates starting what might be considered an "entrepreneurial start-up" business is as low as $0.5 \%$, whilst approximately another $4.5 \%$ of graduates are self-employed. This is a strong indication that the M.Ent. creates a higher percentage of high growth businesses.

\subsection{Start-up Survival Rates in $U K$}

Of the 59 companies created, 49 were still active as of January 2019, i.e. a survival rate of $83 \%$, which is a strong survival rate. Looking at the 47 businesses created between 2002 and 2016 i.e. those that had survived 3 or more years, 39 were still active, indicating a rate of $83 \%$ for a 3-year survival rate. Of 36 businesses started between 2002 and 2014, i.e. those that had survived 5 or more years, 31 were still active with a rate of $86 \%$ for a 5 -year survival rate. This compares very favourably to The Small Business Association (SBA) (2019) data which states that $30 \%$ of new businesses fail during the first two years of being open, 50\% during the first five years and 66\% during the first 10 (3-year survival data not available). In addition, ONS data in UK indicated the 5-year survival rate for businesses born in 2012 and still active in 2017 was 43.2\% (ONS, 2017) with regional variations of $39-45 \%$. This shows that the M.Ent. is not only generating start-ups at a significant rate, but the skills gained is allowing those businesses a better chance of survival compared to UK norms. Comparing this with the survival rate of the non-academic programmes in UK, according to Bone et al. (2019) most UK startups consider the contribution of the incubator/accelerator they attended have been significant or even vital to their success. Start-ups' participation in accelerators is positively correlated with higher survival rates, increased growth in employee numbers and higher amounts of funds raised, though specific numbers are not available, those who attended an incubator (73\%) are likely to report it as significant or vital to their success and those that attended an accelerator (64\%) report it as significant or vital (Bone et al., 2019). In terms of non-UK businesses, only three of the 59 businesses were registered outside the UK despite having a significant number of overseas students on the course, so the UK economy is benefiting from students who have chosen to remain in the UK to advance their business.

\section{Conclusions}

The M.Ent. research programme is proving to be an effective programme. The M.Ent. business creation rate is much above the general population average and the average for recent graduates, although the ratio of male to female founders is just as low as that found in the general population. A key benefit seems to be that the survival rate is between $83 \%$ and $86 \%$ which is very high in comparison to general UK data and is analogous with incubators and accelerators. It provides evidence of sustained development of start-ups and 
entrepreneurial skills rather than just setting up one company. The uniqueness of this programme is that provides an education with a mix of academic knowledge and practical knowledge, offering constant interventions (e.g. assignments, business plan feedback, competitions) to develop their idea. It forces individuals to do primary research and test ideas as part of their dissertation and develop a strong tested/verified business plan and knowledge transfer, which might aid survival rates. It provides students time to think critically, apply the skills taught in the classroom, and assess the validity of their business idea and supportive network of the University's ecosystem hence improving the quality of their work, and equipping them with entrepreneurial and transferable skills. In some cases, graduates that choose not to set-up a start-up immediately upon their graduation, benefited from the M.Ent. programme by finding employment in companies such PWC, Deloitte and The Hut Group. Further work is proposed in identifying the type and discipline of business created, including social enterprises, the background of the students degree prior to joining the M.Ent. and other activities they might have benefitted from whilst at University.

\section{References}

Advance Higher Education (2019). Enterprise and Entrepreneurship in Higher Education. https://www.advance-he.ac.uk/

All Party Parliamentary Group for Entrepreneurship (2018). APPG for Entrepreneurship Report on Enterprise Education, $14^{\text {th }}$ November 2018, https://appgentrepreneurship.org/

Bone, J., Gonzalez-Uribe, J., Haley, C. and Lahr, H. (2019). The Impact of Business Accelerators and Incubators in the UK. BEIS Research Paper Number 2019/009, Department for Business, Energy \& Industrial Strategy, UK.

Gibb, A. (2008). Entrepreneurship and enterprise education in schools and colleges: Insights from UK practice. International Journal of Entrepreneurship Education, 6.

Hart, M., Bonner, K., Heery, L., Prashar, N. and Levie, J. (2018). Global Entrepreneurship Monitor - United Kingdom 2018 Monitoring Report.

Higher Education Statistics Agency (2019). Spin-offs and start-up companies. https://www.hesa.ac.uk/

Klein, P. G. and McCaffrey, M. (2019). Austrian Perspectives on Entrepreneurship, Strategy, and Organization - Elements in Business Strategy. Cambridge University Press - Nicolai J. Foss. doi: 10.1017/9781108777742.

Maresch, D., Harms, R., Kailer, N. and Wimmer-Wurm, B. (2016). The impact of entrepreneurship education on the entrepreneurial intention of students in science and engineering versus business studies university programs. Technological forecasting and social change, 104, 172-179.

Matlay, H. and Carey, C. (2007). Entrepreneurship education in the UK: A longitudinal perspective, Journal of Small Business and Enterprise Development, 14(2), 252-263. 
Office for National Statistics (2017). Business Demography, UK: 2017. https://www.ons.gov.uk/businessindustryandtrade/business/activitysizeandlocation/bulle tins/businessdemography/2017

Quality Assurance Agency for Higher Education (2018). Enterprise and entrepreneurship education guidance for UK higher education providers. https://www.qaa.ac.uk/docs/qaas/enhancement-and-development/enterprise-andentrpreneurship-education-2018.pdf?sfvrsn=15f1f981_8

Papadopoulou, K.A. and Phillips, R.A. (2019). A comparison of on-curricular and offcurricular activities in enterprise education for postgraduate students. Proceedings of the 5th International Conference on Higher Education Advances (HEAd'19), 55-64.

Phillips, R. A. (2018). A Retrospective Study on the Views of Alumni Entrepreneurs Towards University Enterprise Education and Training IUP Journal of Knowledge Management, 16(3), 54-71.

Phillips, R.A. (2010). Encouraging a more enterprising researcher: the implementation of an integrated training programme of enterprise for Ph.D. and postdoctoral researchers, Research in Post-Compulsory Education, 15(3), pp.289-299.

The Small Business Association Website (2019). http://www.sbauk.org/

The University of Manchester (2019). Master of Enterprise (M.Ent.) - Make Ideas Happen. Programme Brochure, Manchester Enterprise Centre. 